\title{
A DIVERSIDADE LINGUÍSTICA NA UNIÃO EUROPEIA
}

\section{LINGUISTIC DIVERSITY IN THE EUROPEAN UNION}

\author{
Ana Raquel Aguiar y Dora Resende Alves \\ Universidade Portucalense Infante D. Henrique, Porto, Portugal
}

\begin{abstract}
Resumo: À semelhança dos direitos humanos, a língua é anterior e externa ao direito, embora com ele estabeleça laços. Ela nasceu com os próprios humanos, mas passa a ser regulada pelo direito. As línguas da União Europeia (UE) são as faladas pela população dos Estados-Membros.

A valorização desta vertente funciona como uma característica que identifica a UE no universo das organizações internacionais e pode ser encontrada nos próprios Tratados institutivos, nos textos de direito derivado, na jurisprudência comunitária e na doutrina, conforme se pode verificar pelos instrumentos utilizados e referenciados neste estudo. E o próprio mote da UE - "Unidos na diversidade" - traduz estes ideais.

É neste quadro jurídico que a diversidade das línguas, salvaguardada desde a primeira hora, surge no direito da UE como um direito e uma característica distintiva desta organização internacional regional.

Esta diversidade e realce contribuem para um património vivo diversificado que constitui tanto um direito como um bem a proteger nos acordos internacionais e na vivência de cada instituição nacional.
\end{abstract}

Palavras-chave: Língua oficial, União Europeia, Diversidade linguística.

\begin{abstract}
Like human rights, language is above and outside the law, although with him establish ties. She was born with humans themselves, but happens to be governed by the law. The languages of the European Union (EU) are spoken by the people of the Member States. Valuing this part works as a feature that identifies the European Union in the world of international organizations and can be found in the very founding treaties, in the secondary legislation texts in the Community case-law and doctrine, as can be seen by the instruments used and referenced in this study. And the EU itself motto - "United in diversity" - reflects these ideals.

It is this legal framework that the diversity of languages, safeguarded from the outset, appears in European Union law as a right and a distinctive feature of this regional international organization.

This diversity and highlight contribute to a diverse living heritage that is both a right and an asset to protect the international agreements and the experience of each national institution.
\end{abstract}

Keywords: Official language, European Union, Linguistic diversity.

\section{Introdução}

A política da União Europeia (UE) promove o multilinguismo, valorizando a diversidade linguística europeia. Assim, a exaltação deste património linguístico rico e diversificado constitui, simultaneamente, um direito e um bem a proteger nos acordos internacionais e na vivência de cada instituição nacional. 
Desta forma, enquanto cidadão europeu, é possível comunicar com as instituições europeias em qualquer uma das línguas oficiais, tendo direito a receber uma resposta na mesma língua.

Considerando a importância da mobilidade e das consequentes relações interculturais, a UE dá particular relevância à aprendizagem de línguas, uma vez que se trata de um meio que facilita a livre circulação das pessoas.

Partindo do pressuposto de que a língua é um dos elementos que constitui a identidade e que contribui para a disseminação da cultura, compreende-se claramente a preocupação da UE em atribuir um impulso crescente ao desenvolvimento da política linguística na Europa.

\section{A língua humana}

Assim como o homem é um ser social (ubi homo, ibi societas) e o direito é inerente à vida humana (ubi societas, ibi ius), a linguagem é uma necessidade e característica humana, como fenómeno social. Ela nasceu com os próprios humanos, supõe-se que em África, e o seu estudo remonta à Antiguidade clássica, conforme resulta dos diálogos de Platão, do século V a.C. ${ }^{1}$, embora se creia que a linguística moderna só se forme no século XVIII².

A linguagem é o principal instrumento de comunicação humano, de partilha com o outro ${ }^{3}$. Antes (e separadamente) da escrita, o homem comunica entre si através da língua. Pode haver linguagem sem escrita associada, seja em povos primitivos, seja em dialetos locais contemporâneos. Existirão mais de 6.000 línguas no Mundo e no continente europeu são falados mais de 60 idiomas. Referimo-nos a línguas faladas, porque existem também as não faladas, ainda que sejam fenómenos muito localizados ${ }^{4}$.

Normalmente, a cada país corresponde uma única língua oficial, mas nem sempre é assim ${ }^{5}$, os países podem ser trilingues, como a Bélgica (com o neerlandês, francês e alemão) ou bilingues, como a Finlândia (com o finlandês e o sueco), isto no universo da União Europeia. Depois, há os países onde, a par da língua oficial,

\footnotetext{
${ }^{1}$ Neves, Maria Amélia Carreiras das. Semiótica, Linguística e Hermenêutica do texto jurídico. 2008, p. 77.

${ }^{2}$ Ibidem, p. 82.

${ }^{3}$ Notável a obra de Johann Gottfried Herder (1744-1803), Ensaio sobre a origem da linguagem, de 1772.

${ }^{4} \mathrm{E}$ descobriu-se ainda a modalidade da língua assobiada, já com experiências catalogadas, com o caso mais recente no turco assobiado da região de Kusköy, na costa do mar Negro. Estas, em termos neuronais, apresentam diferenças na utilização de ambos hemisférios do cérebro. Ver Jornal Público de 26 de agosto de 2015 , p. 24

${ }^{5}$ Siguan, Miquel. A Europa das línguas. 1996, p. 104.
} 
encontramos línguas minoritárias, como na Espanha (com o catalão e o basco) e no Reino Unido (com o gaélico escocês).

A língua é anterior e externa ao direito, embora com ele estabeleça laços. $\mathrm{Na}$ União Europeia, enquanto organização internacional regional, as línguas oficiais são as faladas pela população dos Estados-Membros, sendo que em alguns Estados-Membros são comuns. Incluem não só as línguas oficiais mas também algumas das regionais. As decisões tomadas pelas instituições da UE são traduzidas em todas as línguas oficiais e os cidadãos podem contactar aquelas e solicitar resposta em qualquer uma destas.

A valorização desta vertente funciona como uma característica que identifica a União Europeia no universo das organizações internacionais clássicas, que utilizam apenas umas poucas línguas de trabalho selecionadas, e pode ser encontrada nos próprios Tratados institutivos, nos textos de direito derivado, na jurisprudência comunitária e na doutrina, conforme se pode ver pelos instrumentos utilizados e referenciados neste estudo. E o próprio mote da $\mathrm{UE}^{6}$ - "Unidos na diversidade" - traduz estes ideais.

A preocupação de definir línguas oficiais no seio desta organização internacional surge logo nas Comunidades Europeias que, apesar de terem apenas preocupações setoriais e económicas, assegurou esta faceta logo no primeiro Jornal Oficial em 1958. A diversidade constituiu uma característica intrínseca da construção europeia e também um seu princípio fundamental ${ }^{7}$, pois é através da sua língua que cada povo transmite o seu modo de sentir, que o distingue dos outros povos.

\section{A questão da língua na União Europeia}

A génese da hoje UE aconteceu com respeito pelo pluralismo dos povos da Europa $^{8}$. O uso da língua surge como característica, lema e direito fundamental na UE ${ }^{9}$.

Esta tem 24 línguas oficiais e de trabalho, conforme correspondência ao artigo $55 .^{\circ}$, n. $^{\circ} 1$, do Tratado da União Europeia (TUE) que estabelece as línguas em que este

\footnotetext{
${ }^{6}$ Ver em <http://europa.eu/about-eu/basic-information/symbols/motto/index pt.htm> e Swiebel, Joke. Intercultural dialogue and diversity within the EU. 2008, p. 101.

${ }^{7}$ Silveira, Alessandra e Canotilho, Mariana (coordenação). Carta dos Direitos Fundamentais da União Europeia. 2013, p. 269.

${ }^{8}$ Artigos $1 .^{\circ}$ e $2 .^{\circ}$ do Tratado da União Europeia (TUE).

${ }^{9}$ Livro Branco da Comissão das Comunidades Europeias sobre a Educação e a Formação - Ensinar e aprender - Rumo à sociedade cognitiva COM(95) 590, Novembro de 1995.
} 
se encontra redigido, sendo que o direito desta organização internacional regional protege também as línguas minoritárias ou regionais ${ }^{10}$.

O primeiro regulamento da UE sobre o seu regime linguístico foi aprovado em 1958 e mantém-se em vigor, com alterações ${ }^{11}$, desde logo através de consulta do jornal oficial no endereço eletrónico respetivo ${ }^{12}$. Especificava que as línguas oficiais e de trabalho das então Comunidades Europeias eram o alemão, o italiano, o francês e o neerlandês, isto é, as línguas dos países membros da altura, o que vinha confirmado no artigo 248. ${ }^{\circ}$ do texto originário do Tratado da Comunidade Económica Europeia ${ }^{13}$. À medida que mais países foram aderindo à hoje UE, o número das línguas oficiais e de trabalho foi aumentando. Todavia, o número das línguas referidas é inferior ao dos Estados-Membros, uma vez que algumas são comuns a mais do que um país. Por exemplo, na Bélgica, as línguas oficiais são o alemão, o francês e o neerlandês e, em Chipre, a maioria da população fala grego, que é a língua oficial do país.

$\mathrm{O}$ artigo $3 .^{\circ}$, n. $^{\circ} 3, \S 4 .^{\circ}$, do TUE estabelece, ainda, como princípio estruturante o respeito pela riqueza da diversidade cultural e linguística da União e o artigo 167. ${ }^{\text {, }}$, que a União contribui para o desenvolvimento das culturas dos Estados-Membros.

É neste quadro jurídico que a diversidade das línguas, salvaguardada desde a primeira hora pelo primeiro regulamento ${ }^{14}$, e ainda em vigor (com alterações), surge no direito da UE como um direito e uma característica distintiva desta organização internacional regional.

Esta diversidade e realce contribuem para um património vivo diversificado que constitui tanto um direito como um bem a proteger nos acordos internacionais e na vivência de cada instituição nacional.

A União Europeia tem 24 línguas oficiais e de trabalho, conforme correspondência ao hoje artigo 55. ${ }^{\circ}$, n. $^{\circ} 1$, do TUE que estabelece as línguas em que o tratado se encontra redigido: alemão, francês, neerlandês, italiano (desde 1958),

10 Carta Europeia das Línguas Regionais ou Minoritárias, Estrasburgo [em linha]. 2.X.1992. $<$ http://www.agal-gz.org/portugaliza/tvsptnagaliza/carta linguas.pdf $>$ [20 março 2012].

${ }^{11} \mathrm{O}$ Regulamento $\mathrm{n}{ }^{\circ} 1$ do Conselho, de 15 de Abril de 1958, que estabelece o regime linguístico da Comunidade Económica Europeia. Alterações a este Regulamento pelos: Regulamento (CE) n. ${ }^{\circ}$ 920/2005 do Conselho de 13 de Junho de 2005, em que fixa já 21 línguas oficiais e de trabalho (JOUE L 156 de 18.06.2005, pp. 3 e 4) e Regulamento (CE) n. ${ }^{\circ}$ 1791/2006 do Conselho de 20 de Novembro de 2006, JOUE L 363 de 20.12.2006, p. 1.

${ }^{12}$ Regulamento (UE) n. ${ }^{\circ}$ 216/2013 do Conselho de 4 de março de 2013, relativo à publicação eletrónica do Jornal Oficial da União Europeia. Determina que o Jornal Oficial é publicado sob forma eletrónica, nas línguas oficiais das instituições da União Europeia, JOUE L 69 de 13.03.2013, pp. 1 a 3.

${ }^{13}$ Sem correspondência na versão atual, pelo Tratado de Lisboa, do Tratado sobre o Funcionamento da União Europeia (TFUE).

${ }^{14}$ Regulamento n. ${ }^{\circ} 1$ do Conselho, de 1958 mencionado. 
dinamarquês, inglês (desde 1973), grego (desde 1981), português, espanhol (desde 1986), finlandês, sueco (desde 1995), checo, eslovaco, esloveno, estónio, húngaro, letão, lituano, maltês, polaco (desde 2004), búlgaro, irlandês, romeno (desde 2007) e com a inclusão do croata em 2013 pelas alterações do Tratado de Adesão da Croácia à $\mathrm{UE}^{15}$. O facto de uma língua ter estatuto de "língua oficial e de trabalho" implica, sobretudo, que a correspondência com as instituições da UE pode processar-se em qualquer uma das línguas em causa e que os regulamentos e outros documentos legislativos da UE são publicados, nomeadamente no Jornal Oficial, em todas as línguas oficiais e de trabalho.

Devido a condicionalismos de tempo e orçamentais, relativamente poucos documentos de trabalho são traduzidos para todas as línguas. Regra geral, a Comissão Europeia utiliza o inglês, o francês e o alemão como línguas processuais, enquanto as línguas das traduções que o Parlamento Europeu fornece variam consoante as necessidades dos deputados. Houve já um momento em que se apurou que $55 \%$ dos textos eram redigidos em inglês. Curiosamente, as línguas de trabalho da UE não coincidem já com as línguas mais faladas no mundo, onde apenas o inglês se insere (com 328 milhões), pois equipara-se ao espanhol (com 329 milhões) e todas superadas pelo mandarim (com 845 milhões) ${ }^{16}$. O alemão já representa apenas 90 milhões e o francês não tem sequer relevância entre as 10 línguas mais faladas.

É portanto curioso notar que esta faculdade de a UE permitir a utilização de 24 línguas oficiais surge como caracterizadora desta organização internacional, talvez de uma forma ímpar ${ }^{17}$.

\section{A língua para o conhecimento do direito da União Europeia}

No contexto descrito, cada cidadão europeu tem acesso ao direito da UE na sua própria língua como resultado do seu estatuto de cidadania ${ }^{18}$. Porém, o domínio de mais

\footnotetext{
${ }^{15}$ Nomeadamente alterando o artigo 52. ${ }^{\circ}$ do TUE, no JOUE L 112 de 24.04.2012 com o Tratado de Adesão da Croácia à União Europeia, assinado em 9 de Dezembro de 2011, concretizado em 1 de Julho de 2013.

16 Dados de 2014 em <http://observatorio-lp.sapo.pt/pt/dados-estatisticos-as-linguas-mais-faladas/10-

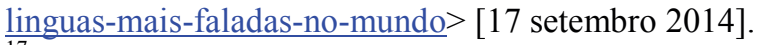

17 Basta consultar os endereços oficiais de grandes organizações internacionais para verificar a dificuldade de acesso em qualquer língua de Estados-Membros dessas mesma organizações (ONU -UEO -EFTA-OCDE).

${ }^{18}$ Resolução do Parlamento Europeu 2013/C 257 E/10, de 29 de março de 2012, referente ao Relatório de 2010 sobre a cidadania da União - Eliminar os obstáculos ao exercício dos direitos dos cidadãos da UE, JOUE C 257 E de 15.06.2012, pp. 74 a 84.
} 
do que uma língua é relevante para o desempenho de determinadas funções, por exemplo, as profissões ligadas à prática do direito.

Uma vez que cada Estado-Membro tem a sua própria língua e o seu sistema jurídico específico, o Tribunal de Justiça da União Europeia é necessariamente uma instituição multilingue. O seu regime linguístico não tem equivalente em nenhuma outra jurisdição do mundo, visto que cada uma das línguas oficiais da União pode ser língua de processo. O Tribunal de Justiça é, com efeito, obrigado a respeitar um multilinguismo integral devido à necessidade de comunicar com as partes na língua do processo e de assegurar a difusão da sua jurisprudência em todos os Estados-Membros.

Aliás, também os tribunais nacionais são parte do sistema judiciário da UE, como tribunais funcionais de aplicação do direito da União. A UE é uma "comunidade de direito" 19 , conforme entendimento já de há muito do Tribunal de Justiça da UE, que se concretiza também através dos seus aplicadores que são os juízes e profissionais do foro nacionais, que constituem agentes essenciais do sistema jurisdicional da União Europeia, nomeadamente nos casos de aplicabilidade direta das suas normas.

A língua é, então, o principal utensílio dos agentes da justiça ${ }^{20}$. Por estas razões, no âmbito da formação judiciária, nos termos dos artigos $81 .^{\circ}$ e $82 .^{\circ}$ do TFUE, a formação multilinguística surge muito importante, uma vez que estudos demonstram que apenas um número relativamente reduzido de juízes fala uma língua estrangeira suficientemente bem para poder participar ativamente na formação judiciária em outros Estados-Membros $^{21}$. Dito de outra forma, o atual nível de formação em línguas estrangeiras, também em conjugação com o atual nível de conhecimento do direito comunitário, aliás, é insuficiente e limita o pleno exercício das possibilidades de cooperação judiciária. A necessidade de aumentar o conhecimento geral dos juízes nacionais em matéria de línguas estrangeiras é urgente porque é do interesse público

\footnotetext{
${ }^{19}$ No Acórdão do TJCE de 23 de 1986, Les Verts / Parlamento Europeu, Proc. C-294/83, Colect. 1986, p. $1339, \S 23$.

${ }^{20}$ Resolução do Parlamento Europeu de 9 de Julho de 2008, sobre o papel do juiz nacional no sistema jurisdicional europeu, P6_TA(2008)0382, § 3, e Comunicação 2011/C 308/06 da Comissão sobre boas práticas para a instrução de processos de aplicação dos artigos $101 .^{\circ}$ e $102 .^{\circ}$ do Tratado sobre o Funcionamento da União Europeia, JOUE C 308 de 14.10.2011, pp. 6 a 32.

${ }^{21}$ Resolução do Parlamento Europeu 2013/C 251 E/07 de 14 de março de 2012 sobre formação judiciária, JOUE C 251 E de 31.08.2013, p. 44. Ainda em julho de 2014 foi lançada pela Comissão uma chamada de projetos para preparação de juízes nacionais nesta temática, onde se abrem diversos aspetos em que os tribunais nacionais lidam diretamente com o direito da União Europeia, com um orçamento de um milhão de euros. Uma das áreas previstas foi precisamente o desenvolvimento das habilitações linguísticas legais dos juízes nacionais.
} 
europeu desenvolver as competências linguísticas dos membros do poder judicial dos Estados-Membros, por exemplo, através de intercâmbio judiciário ${ }^{22}$.

\section{A promoção do conhecimento de línguas na União Europeia}

Torna-se tão mais relevante o conhecimento de mais do que uma língua quanto ainda nos dias de hoje se comprova que, por exemplo, 61\% dos portugueses não fala nenhuma língua estrangeira, segundo dados do Eurobarómetro ${ }^{23}$. Isto é, a meta traçada, já em 1995 pela União Europeia, de colocar os cidadãos a dominar três línguas estrangeiras, não foi de todo alcançada, embora certamente se encontrem grandes diferenças na realidade de país para país ${ }^{24}$.

Por essa razão, assistimos, nas mais variadas áreas de intervenção, à preocupação da UE em promover a diversidade linguística, mas associar-lhe o conhecimento intercultural e a própria promoção da mobilidade ${ }^{25}$. O conhecimento de línguas de outro país, no seio da UE, promove o próprio processo de integração. Uma cidadania ativa, a participação cívica, o papel das organizações da sociedade civil, a tolerância e compreensão mútua dos cidadãos serão tanto mais atingidos quanto mais for possível um diálogo intercultural que será mais eficaz com o conhecimento de línguas estrangeiras ${ }^{26}$.

Tanto mais eficaz será a promoção do multiculturalismo e do multilinguismo quanto o ensino de uma outra língua oficial se efetue em tenra idade, sendo que as crianças dispõem de uma capacidade natural para tal aprendizagem e o pluralismo linguístico é uma mais-valia para todos os jovens europeus ${ }^{27}$.

E só será possível a construção de um verdadeiro espaço judicial europeu se, para além do conhecimento do direito europeu, o conhecimento das línguas permitir a

\footnotetext{
${ }^{22}$ Resolução do Parlamento Europeu P6_TA(2008) 0382, cit., § 6.

${ }^{23}$ Jornal $i$ de 26 de Agosto de 2015, Suplemento Educa, pp. 2 e 15.

${ }^{24}$ Livro Branco da Comissão das Comunidades Europeias sobre a Educação e a Formação - Ensinar e aprender - Rumo à sociedade cognitiva COM(95) 590, Novembro de 1995, p. 49.

${ }^{25}$ Comunicação da Comissão ao Parlamento Europeu, ao Conselho, ao Comité Económico e Social Europeu e ao Comité das Regiões com o Programa da UE em matéria de justiça para 2020: reforçar a confiança, a mobilidade e o crescimento na União de 11.03.2014, documento COM (2014) 144 final, p. 5.

${ }^{26}$ Por exemplo, o Programa "Europa para os Cidadãos" 2007-2013, cuja avaliação consta do Relatório da Comissão ao Parlamento Europeu, ao Conselho, ao comité Económico e Social Europeu e ao Comité das Regiões sobre a execução, os resultados e a avaliação global daquele, no documento $\operatorname{COM(2015)~} 652$ final, Bruxelas, 16.12.2015.

27 Resolução do Parlamento Europeu 2016/C 093/07, de 11 de setembro de 2013, sobre as línguas europeias ameaçadas de extinção e a diversidade linguística na União Europeia, JOUE C 93 de 09.03.2016, p. 54, § U.
} 
divulgação e apreensão dos conhecimentos e da cooperação ${ }^{28}$, de onde resulta a enorme relevância da aprendizagem de línguas para determinadas profissões como seja na formação dos profissionais do foro ${ }^{29}$.

\section{A língua enquanto direito fundamental}

O direito originário veio consagrar um elenco inicial dos direitos que integram o estatuto de cidadania europeia, no artigo $20 .^{\circ}$, n. $^{\circ}$ 2, alínea d), do $\mathrm{TFUE}^{30}$, depois replicado no artigo $41 .^{\text {o31 }}$ da Carta dos Direitos Fundamentais da União Europeia ${ }^{32}$, nomeadamente, ao dispor como direito fundamental o Direito a uma boa

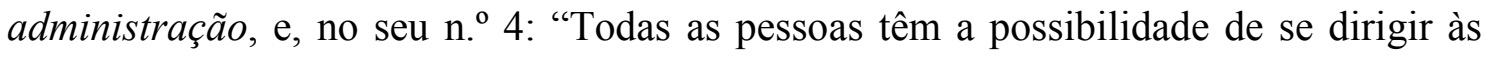
instituições da União numa das línguas dos Tratados, devendo obter uma resposta na mesma língua".

Para que o direito de cada cidadão da União a se dirigir às instituições europeias em qualquer língua oficial da União seja integralmente respeitado e aplicado, há que velar por que todas as consultas públicas sejam objeto de um tratamento equitativo e por que não se verifiquem discriminações linguísticas entre as consultas ${ }^{33}$, relacionando-se, então, diretamente a aplicação do regime linguístico com a política de acesso aos documentos da UE.

Tendo em conta este direito dos cidadãos europeus, é possível encontrarmos determinações específicas a corroborá-lo em algumas matérias, como é o caso do contencioso nas instâncias comunitárias, ou em documentos muito específicos, como, por exemplo, em matéria de inspeções às empresas nas averiguações efetuadas pela Comissão ao abrigo das normas de direito da concorrência, permitindo às empresas

\footnotetext{
${ }^{28}$ Resolução do Parlamento Europeu 2009/C 294 E/06, de 9 de Julho de 2008, sobre o papel do juiz nacional no sistema jurisdicional europeu, JOUE C 294 E de 03.12.2009, p. 30 e Resolução do Parlamento Europeu 2013/C 251 E/07 de 14 de março de 2012 sobre formação judiciária, nos termos dos artigos 81. ${ }^{\circ}$ e 82..$^{\circ}$ do TFUE, JOUE C 251 E de 31.08.2013, pp. 42 a 44.

${ }^{29}$ Resolução do Parlamento Europeu 2016/C 024/12, de 7 de fevereiro de 2013, sobre formação judiciária - coordenadores nos tribunais, JOUE C 24 de 22.01.2016, p. 99.

${ }^{30}$ Porto, Manuel Lopes e Anastácio, Gonçalo (coordenação). Tratado de Lisboa - anotado e comentado. 2012, p. 260.

${ }^{31}$ Silveira, Alessandra e Canotilho, Mariana (coordenação). Carta dos Direitos Fundamentais da União Europeia - comentada. 2013, p. 489.

${ }^{32}$ No Jornal Oficial da União Europeia C 326/391 de 26.10.2012. O texto retoma, adaptando-a, a Carta proclamada em 7 de dezembro de 2000 e substitui-a a partir da data de entrada em vigor do Tratado de Lisboa.

${ }^{33}$ Resolução do Parlamento Europeu 2013/C 332 E/12, JOUE C 332 E de 15.11.2013, p. 68.
} 
utilizar a língua do país membro em que estão sedeadas para as comunicações com a Comissão ${ }^{34}$.

Tendo em conta que os tribunais nacionais são tribunais funcionalmente da União, que aplicam o direito da UE em cooperação judiciária plena, há vertentes, como seja a aplicação da justiça penal, em que a questão da língua periga o implementar e efetivar de outros direitos fundamentais ${ }^{35}$.

E, antes disso, o artigo $22 .^{{ }^{3} 6}$ da Carta, estabelece a Diversidade cultural, religiosa e linguística, embora em moldes um pouco brandos: “A União respeita a diversidade cultural, religiosa e linguística".

\section{O respeito pela diversidade cultural e linguística}

A consagração da língua como direito fundamental vai mais longe no direito da União Europeia, visto que a diversidade é inerente à construção europeia ${ }^{37}$. Assim, a União Europeia tem uma preocupação com a língua enquanto fator de inclusão e exclusão que se estende às línguas regionais e minoritárias ${ }^{38}$, aí, de novo, com recurso ao citado artigo $22 .^{\circ}$ da Carta.

Bem assim, ao mencionado artigo $55^{\circ}$, n. $^{\circ} 1$, do TUE teremos que acrescentar a consulta do seu n. $^{\circ}$, aditado pelo Tratado de Lisboa, que se refere à possibilidade de tradução oficial do Tratado para qualquer outra língua que os Estados-Membros determinem, disposição que se deverá ler com a Declaração $n .^{\circ} 16$ anexa ao Tratado de Lisboa, no respeito pela riqueza da diversidade cultural e linguística da União.

Na União Europeia, contam-se mais de 60 comunidades autóctones que falam uma língua regional ou minoritária. Estima-se em cerca de 40 milhões o número de cidadãos da UE que utiliza regularmente uma língua regional ou minoritária ${ }^{39}$. Daí que o Parlamento Europeu exorte à adoção de medidas políticas concretas para a proteção

\footnotetext{
${ }^{34} \mathrm{Na}$ Comunicação 2011/C 308/06 da Comissão sobre boas práticas para a instrução de processos de aplicação dos artigos $101 .^{\circ}$ e $102 .^{\circ}$ do Tratado sobre o Funcionamento da União Europeia, JOUE C 308 de 14.10.2011, p. 12, 2.4.

${ }^{35}$ Recomendação do Parlamento Europeu 2010/C 212 E/19, de 7 de maio de 2009, referente ao desenvolvimento de um espaço de justiça penal na UE, JOUE C 212 E de 05.08.2010, p. 120, 1.a) § 1, e p. $122, \S 5$.

${ }^{36}$ Silveira, Alessandra e Canotilho, Mariana (coordenação). Carta dos Direitos Fundamentais da União Europeia - comentada. 2013, p. 269.

${ }^{37}$ Ibidem, p. 269.

${ }^{38}$ Melo, Helena Pereira de. O direito a não se ser discriminado em razão da língua. 1999, ponto 1.2.2.

${ }^{39}$ A definição de língua regional ou minoritária dada por muitos Estados-Membros da UE é a utilizada na Carta Europeia das Línguas Regionais e Minoritárias um tratado assinado no âmbito do Conselho da Europa, em Estrasburgo, em 5 de Novembro de 1992.
} 
das línguas ameaçadas, apelando ao multilinguismo e fomentando a intercompreensão linguística ${ }^{40}$.

Por esta razão, as instituições, nomeadamente o Conselho, preocupam-se especificamente em fixar a utilização de línguas adicionais ${ }^{41}$. A diversidade linguística é um elemento fundamental da cultura europeia e do diálogo intercultural, e a capacidade de comunicar numa língua que não a língua materna é reconhecida como uma das competências essenciais que os cidadãos devem procurar adquirir ${ }^{42}$.

\section{A publicação do Jornal Oficial da União Europeia}

A publicação do Jornal Oficial da União Europeia acompanha passo a passo a matéria de diversidade linguística na União Europeia. A existência de diversas línguas na União Europeia representa uma dificuldade para o acesso à legislação a nível europeu, visto que uma determinada informação catalogada só é realmente útil se o utilizador a puder entender ${ }^{43}$. Os serviços de tradução, que garantem que a legislação adotada a nível da UE seja diretamente compreensível e comunicada em simultâneo em todas as línguas da União, enfrentam um desafio ainda mais difícil pela própria natureza das informações jurídicas.

A 23 de Julho de 1952, com a entrada em vigor do Tratado CECA, prepara-se a publicação do Jornal Oficial da Comunidade Europeia do Carvão e do Aço.

A publicação desenvolve-se na década de $60^{44}$ e é em 1969 que o Serviço das Publicações Oficiais das Comunidades Europeias, editora das instituições, agências e outros órgãos da União Europeia, se constitui oficialmente como órgão independente no Luxemburgo $^{45}$. Embora o Serviço só se tenha constituído oficialmente como órgão

\footnotetext{
${ }^{40}$ Resolução do Parlamento Europeu 2016/C 093/07, cit., p. 55.

${ }^{41}$ Conclusões do Conselho 2005/C 148/01 de 13 de Junho de 2005 sobre a utilização de línguas adicionais no Conselho, JOUE L 148 de 18.06.2005, pp. 1 e 2.

${ }_{42}$ Conclusões do Conselho 2014/C 183/05, de 20 de maio de 2014, sobre o multilinguismo e o desenvolvimento de competências linguísticas, JOUE C 183 de 14.06.2014, p. 26.

${ }^{43}$ Relatório do Conselho sobre o acesso à legislação. 2015/C 97/03, JOUE C 97 de 24.03.2015, pp. 5 e 3.

${ }^{44}$ Marrana, Rui Miguel. "O acesso à informação...". In: Revista de Ciências Empresariais e Jurídicas. p. 19.

${ }^{45}$ Este organismo fora previsto pela Decisão de 8 de Abril de 1965 (JO 152 de 13.07.1967, p. 18), aplicada pela Decisão n. ${ }^{\circ}$ 69/13 (JOCE L 13 de 18.01.1969, p. 19, alterada pela Decisão n. ${ }^{\circ}$ 80/443/CEE, Euratom, CECA).

A sua organização e modo de funcionamento actuais foram estabelecidos por um acordo interinstitucional, Decisão 2000/459/CE, CECA, Euratom, de 20 de Julho de 2000 relativa à organização e ao funcionamento do Serviço das Publicações Oficiais das Comunidades Europeias (JOCE L 183 de 22.07.2000, pp. 12 a 15), que revoga a anterior Decisão n. ${ }^{\circ} 69 / 13$.

Aplicável a Decisão 2012/368/UE, Euratom do Parlamento Europeu e do Conselho, da Comissão, do Tribunal de Justiça da União Europeia, do Tribunal de Contas, do Comité Económico e Social Europeu e do Comité das Regiões de 29 de junho de 2012 (JOUE L 179 de 11.07.2012, pp. 15 e 16)
} 
independente em 1969, as suas origens remontam ao serviço das publicações da Comunidade Europeia do Carvão e do Aço, que publicou o Jornal Oficial da Comunidade Europeia do Carvão e do Aço a partir de 1952, publicado o primeiro número em quatro línguas (alemão, francês, italiano e neerlandês) em 30 de Dezembro de $1952^{46}$. A Internet teve um impacto considerável no aumento da difusão da informação comunitária em grande parte alimentada e gerida pelo Serviço das Publicações no portal integrado de legislação EUR-Lex/CELEX, plataformas em funcionamento que disponibilizam direta e gratuitamente todo o direito europeu ${ }^{47}$.

Com a entrada em vigor do primeiro alargamento das Comunidades, a 1 de Janeiro de 1973, o Jornal Oficial das Comunidades Europeias passa a ser publicado em 6 línguas (até aí era-o em 4). Em 1 de Janeiro de 1986, com a entrada em vigor do terceiro alargamento das Comunidades, passa a ser publicado em 9 línguas (até aí era-o em 7). Mais tarde, com a entrada em vigor do quarto alargamento das Comunidades, a 1 de Janeiro de 1995, passa para 11 línguas (até aí era-o em 9). A 1 de Fevereiro de 2003, com a entrada em vigor do Tratado de $\mathrm{Nice}^{48}$, altera-se a designação do Jornal Oficial das Comunidades Europeias para Jornal Oficial da União Europeia ${ }^{49}$, por força da alteração do atual artigo 297..$^{\circ}$ TFUE pelo Tratado de Nice.

Os jornais oficiais estão assim disponíveis nas línguas oficiais dos EstadosMembros a partir da data da respetiva adesão - hoje 24 línguas ${ }^{50}$. A legislação em vigor na data da adesão é traduzida e publicada em edições especiais.

Desde 1998, está disponível na base EUR-Lex uma versão eletrónica com todas as edições impressas.

A partir de 1 de julho de 2013 apenas a edição electrónica do Jornal Oficial faz fé e produz efeitos jurídicos ${ }^{51}$, no endereço electrónico http://eur-lex.europa.eu .

que altera a Decisão 2009/496/CE, Euratom relativa à organização e ao funcionamento do Serviço das Publicações da União Europeia que é um serviço interinstitucional que tem por objeto assegurar, nas melhores condições possíveis, a edição das publicações das instituições da União Europeia, a fim de a adaptar às disposições dos Tratados, tal como alterados pelo Tratado de Lisboa, e, em especial, de acrescentar o Conselho Europeu como instituição signatária (de 26 de Junho de 2009, JOUE L 168 de 30.06.2009, pp. 41 a 47).

${ }_{46}$ Desde 30 de Dezembro de 2002, constituiu-se um fundo documental com os cinquenta anos de produção editorial da CECA. Folheto AO-51-03-447-PT-D, Serviço de Publicações em [em linha] $<$ http://publications.eu. $>$ [12 novembro 2008].

${ }^{47}$ Marrana, Rui Miguel. "O acesso à informação...". In: Revista de Ciências Empresariais e Jurídicas. p. 20.

${ }^{48}$ Pelo depósito do último instrumento de ratificação em 18 de Dezembro de 2002 (2003/C 24/04, JOCE C 24 de 31.01.2002). Ver JOCE L 23 de 28.01.2003.

${ }^{49} \mathrm{O}$ primeiro publicado com a nova designação foi o JOUE L 27 de 01.02.2003.

${ }^{50}$ Relatório do Conselho 2015/C 97/03, cit., p. 3. 
O princípio da publicidade dos atos da UE pretende servir os princípios da legalidade, da igualdade e proibição do arbítrio, da transparência e da segurança jurídica e da proteção da confiança dos cidadãos e residentes da UE.

O conjunto de todo o direito comunitário forma o acervo comunitário ou acquis communautaire, que todos os Estados-Membros devem respeitar e a que qualquer candidato a Estado-Membro tem que aderir como um todo, daí a importância deste meio de conhecimento. O acesso à legislação é, portanto, crucial no contexto da União Europeia $^{52}$ e, crê-se, fica bem assegurado.

\section{Conclusão}

$\mathrm{Na}$ União Europeia, enquanto organização internacional, talvez de uma forma ímpar, a diversidade de línguas foi, desde o primeiro momento, encarada como uma circunstância fundadora e os meios foram preparados para fazer chegar a todos os membros o direito e o conhecimento. O endereço oficial da UE é um exemplo claro de como a diversidade linguística não é um entrave. Porém, não de modo absoluto, há ainda documentos de trabalho, e mesmo finais, que não se encontram em todas as línguas.

Por um lado, esta faceta de acessibilidade acarreta custos elevados e um exigente trabalho simultâneo de tradução e, por outro lado, cada vez mais algumas línguas se tornam de uso universal, como o inglês e o espanhol, porém, aplaude-se o funcionamento permanente e quase abrangente das informações da União Europeia em todas as línguas reconhecidas como oficiais e a proteção pelas línguas minoritárias. Também, cada vez mais este aspeto de acessibilidade ao direito e ao conhecimento é tido em conta na documentação produzida.

Ainda assim, há um caminho a trilhar no sentido da formação em matéria de línguas estrangeiras, não só dos profissionais do direito, como da população em geral.

\footnotetext{
${ }^{51}$ Nos termos do Regulamento (UE) n. ${ }^{\circ}$ 216/2013 do Conselho, cit., e Relatório do Conselho 2015/C 97/03, cit., p. 3.

${ }^{52}$ Relatório do Conselho 2015/C 97/03, cit., p. 3.
} 


\section{Referências Bibliográficas}

Alves, Dora Resende. "As cooperações reforçadas na União Europeia", Para Jorge Leite. II Volume. Coimbra Editora, 2014, pp. 7-17. ISBN 978-972-32-2260-9.

Campos, João Mota de; Pereira, António Pinto; Campos, João Luiz. $O$ direito processual da União Europeia - contencioso comunitário. Lisboa: Fundação Calouste Gulbenkian. 2. ${ }^{a}$ ed. revista e aumentada, 2014. ISBN 978-972-311516-1.

Gonçalves, Susana. "O regime linguístico na União Europeia” in a folha N. ${ }^{\circ} 25$ Número especial. 2007, pp. 27.

Gorjão-Henriques, Miguel. Direito da União - história, direito, cidadania, mercado interno e concorrência. Coimbra: Livraria Almedina. 7. ${ }^{\circ}$ ed., 2014. ISBN 978972-40-5554-1.

------ Tratado de Lisboa. 5. a ed. Coimbra: Livraria Almedina, 2014. ISBN 978-972-405445-2.

Gouveia, Jorge Bacelar e Coutinho, Francisco Pereira. Enciclopédia da Constituição Portuguesa. Quid Juris Editora, 2013. ISBN 978-972-724-642-7.

Herder, Johann Gottfried. Ensaio sobre a origem da linguagem. Editora Antígona, 1987.

Machado, Jónatas E. M.. Direito da União Europeia. Coimbra: Wolters Kluwer | Coimbra Editora. 2010. ISBN 978-972-32-1858-9.

Marrana, Rui Miguel. “O acesso à informação no quadro do funcionamento da União Europeia" in Revista de Ciências Empresariais e Jurídicas. Instituto Superior de Contabilidade e Administração do Porto, n. ${ }^{\circ}$ 21, 2012, pp. 7 a 42. ISSN 1646-1029.

Melo, Helena Pereira de. O direito a não se ser discriminado em razão da língua. III Seminário sobre Reabilitação da Criança Surda, Porto, 1999.

Neves, Maria Amélia Carreiras das. Semiótica, Linguística e Hermenêutica do texto jurídico. Instituto Piaget, 2008. ISBN 978-989-659-032-1.

Parlamento Europeu. 50 Anos de Europa - os grandes textos da construção europeia. 2. ${ }^{\mathrm{a}}$ ed. 2001. ISBN 972-97048-3-X.

Parlamento Europeu. Resolução 2016/C 093/07, de 11 de setembro de 2016, sobre as línguas europeias ameaçadas de extinção e a diversidade linguística na União Europeia, JOUE C 93 de 09.03.2016, pp. 52 a 58. 